\title{
Comparison of graduate-entry and direct school leaver student performance on an applied dental knowledge test
}

\section{Urzinger, Sebastian}

http://hdl.handle.net/10026.1/5413

10.1111/eje.12232

European Journal of Dental Education

Wiley

All content in PEARL is protected by copyright law. Author manuscripts are made available in accordance with publisher policies. Please cite only the published version using the details provided on the item record or document. In the absence of an open licence (e.g. Creative Commons), permissions for further reuse of content should be sought from the publisher or author. 
"This is a final author's draft of the paper submitted for publication in European Journal of Dental Education 2016 (DOI: 10.1111/eje.12232)

Title:

Comparison of Graduate-entry and Direct School Leaver Student Performance on an Applied Dental Knowledge Test

K. Ali ${ }^{1}$, D Zahra ${ }^{2}$, C. Tredwin ${ }^{3}$

1. ${ }^{1}$ Associate Professor and Consultant in Oral Surgery, Peninsula Dental School, Plymouth University,

2. ${ }^{2}$ Senior Psychometrician Plymouth University Peninsula Schools of Medicine and Dentistry,

3. ${ }^{3}$ Head of Peninsula Dental School, Plymouth University;

Correspondence Author: Kamran Ali

Peninsula Dental School

Portland Square

University of Plymouth

Drake Circus

Plymouth

PL4 8AA

E-mail: kamran.ali@plymouth.ac.uk 


\section{Abstract:}

Aims: To compare the academic performance of graduate-entry and direct school leavers in an undergraduate dental programme.

Methods: This study examined the results of students in applied dental knowledge (ADK) progress tests conducted during two academic years. A mixed model analysis of variance (ANOVA) was conducted to compare the performance of graduate-entry and direct school leavers. ADK was treated as a repeated measures variable, and the outcome variable of interest was percentage score on the ADK.

Results: The results show statistically significant main effects for $\operatorname{ADK}[F(1,113)=$ 61.58, $\left.p<0.001, \eta^{2} \mathrm{p}=.35\right]$, Cohort $\left[F(1,113)=88.57, p<0.001, \eta^{2} \mathrm{p}=.44\right]$, and Entry $[F$ $\left.(1,113)=11.31, p=0.001, \eta^{2} \mathrm{p}=.09\right]$. That is, students do better on each subsequent test (main effect of $A D K$ ), students in later years of the programme perform better than those in earlier years (main effect of cohort), and graduate-entry students out-perform direct school leavers.

Conclusions: This is the first study to explore the differences in the academic performance of graduate-entry and direct school leavers in an undergraduate dental programme. The results show that the academic performance of graduate students was better than the direct school leavers in years 2 and 3 . Further research is required to compare the performance of students longitudinally across the entire duration of undergraduate dental programmes and evaluate whether this difference persists throughout. 


\section{Introduction}

Medical and Dental schools in the United Kingdom (UK) follow a competitive admission criteria and offer admission to both undergraduate (direct school leavers) as well as graduate students (1). There is an ongoing debate comparing the strengths and weaknesses of graduate and undergraduate entrants to the medical schools (2). In this regard, a range of attributes of medical students have been investigated including academic achievement $(3,4)$, clinical performance $(5,6)$, research performance $(7)$, and personality profiles $(8,9)$. However, there is a dearth of published literature investigating the effects and implications of graduate- and direct school leaver-entry criteria in undergraduate dental education.

The aim of this study was to compare the academic performance of graduate- and undergraduate-entrants on applied dental knowledge tests at a dental school in the UK. Our dental school is based in primary care settings and follows an enquiry-based, student-led curriculum $(10,11)$. The school followed a graduate-entry criterion to its four-year Bachelor of Dental Surgery (BDS) programme until 2012. Subsequently, the BDS programme was extended to five years allowing entry to direct school leavers (DSL) with ten percent of admissions reserved for graduate students.

Academic assessment of dental students at our institution is based on progress tests measuring their applied dental knowledge (ADK). Progress testing is a form of longitudinal feedback-oriented assessment initially used by Maastricht University for the assessment of medical students (12) and later embraced by other medical schools $(13,14)$. Our institution was the first dental school to use progress testing in an undergraduate dental programme (15). Students are tested on multiple occasions each year and the results combined to determine the growth of knowledge for each 
student, enabling more reliable and valid decision making regrading student progression (16). We have used progress test for summative assessment of applied dental knowledge of undergraduate dental students for several years (17). The standard of dental progress tests is set at the level of knowledge expected from a newly qualified dental graduate. Students from year 2 and all subsequent years sit the same test simultaneously and tests are repeated twice a year.

This study investigated the differences in academic performance of graduate versus direct school leavers in dental progress tests. 


\section{Methods}

Historic examination data related to four progress test sittings to assess applied dental knowledge conducted over a period of two years (2014-15) for students enrolled on the new five-year programme was collated. Tests numbered ADK15 and16 were conducted in 2014 and year 2 students (53 direct school leavers, 8 graduates) from the 2013-14 entry cohort were assessed. Tests 17 and 18 were conducted in 2015 and students in the 2013-14 cohort, now Year 3; (54 direct school leavers, 8 Graduates) and 2014-15 cohort in Year 2 (45 direct school leavers, 10 graduates) undertook these tests.

\section{Data Analysis}

Focussing on only the 2013-14 cohort in order to assess the effect of entry type across all four tests a 2 Entry (Graduate and Direct School Leavers) x 4 ADK (ADK15, ADK16, ADK17, ADK18) mixed ANOVA was conducted.

Furthermore, in order to explore the impact of entrant type across tests and cohorts for which data was available, a 2 ADK (ADK17, ADK18) x 2 Cohort (2013-14, 201415) $\times 2$ Entry (Graduate and Direct School Leavers) mixed model ANOVA was conducted.

In both cases, ADK was treated as a repeated measures variable, and the outcome variable of interest was percentage score on the ADK. Levene's test was conducted to assess equality of variance in the two groups based on Entry types. All statistics were computed using SPSS (IBM Corp. Released 2013. IBM SPSS Statistics for Windows, Version 22.0 Armonk, NY: IBM Corp.) R was used to depict differences in percentage ADK scores (18). 


\section{Results}

The analysis of the 2013-14 cohort scores across Entry types and the four ADK tests revealed a statistically significant effect of $\operatorname{ADK}\left[F(3,177)=83.52, p<0.001, \eta^{2} p=.59\right]$ whereby students performed better on subsequent tests. Despite graduate-entry students outperforming direct school leavers by $5.17 \%$ on average across the four tests, the main effect of Entry was not statistically significant. Entry type and ADK showed no interaction, indicating the consistency of this difference between entry types; for all tests taken by the 2013-14 cohort, graduate-entry students out-perform direct school leavers, though when looking at these tests and this cohort in isolation, this consistent difference does not quite reach statistical significance $[F(1,59)=2.75$, $\left.p=0.10, \eta^{2} \mathrm{p}=.05\right]$.

Broadening this analysis to consider this difference across different cohorts, the comparison of ADK17 and ADK18 scores reveals statistically significant main effects for $\operatorname{ADK}\left[F(1,113)=61.58, p<0.001, \eta^{2} p=.35\right]$, Cohort $[F(1,113)=88.57, p<0.001$, $\left.\eta^{2}=.44\right]$, and Entry $\left[F(1,113)=11.31, p=0.001, \eta^{2} p=.09\right]$, but no significant interactions. That is, students do better on each subsequent test (main effect of ADK), students in later years of the programme perform better than those in earlier years (main effect of cohort), and of most relevance to his paper, graduate-entry students out-perform direct school leavers. Levene's test to assess equality of variance in the two groups was also non-significant. The lack of interaction between these factors suggests that the differences in performance are invariant across combinations of ADK, cohort and entry types; that is, irrespective of which cohort the students are from, or which test is taken, graduate-entry students out-perform direct school leavers. These effects can be seen in Figure 1 and means and SDs for each cell of the design are presented in Table 1. 
Figure 1 Plot depicting mean score (percentage) by ADK test, cohort, and entry type

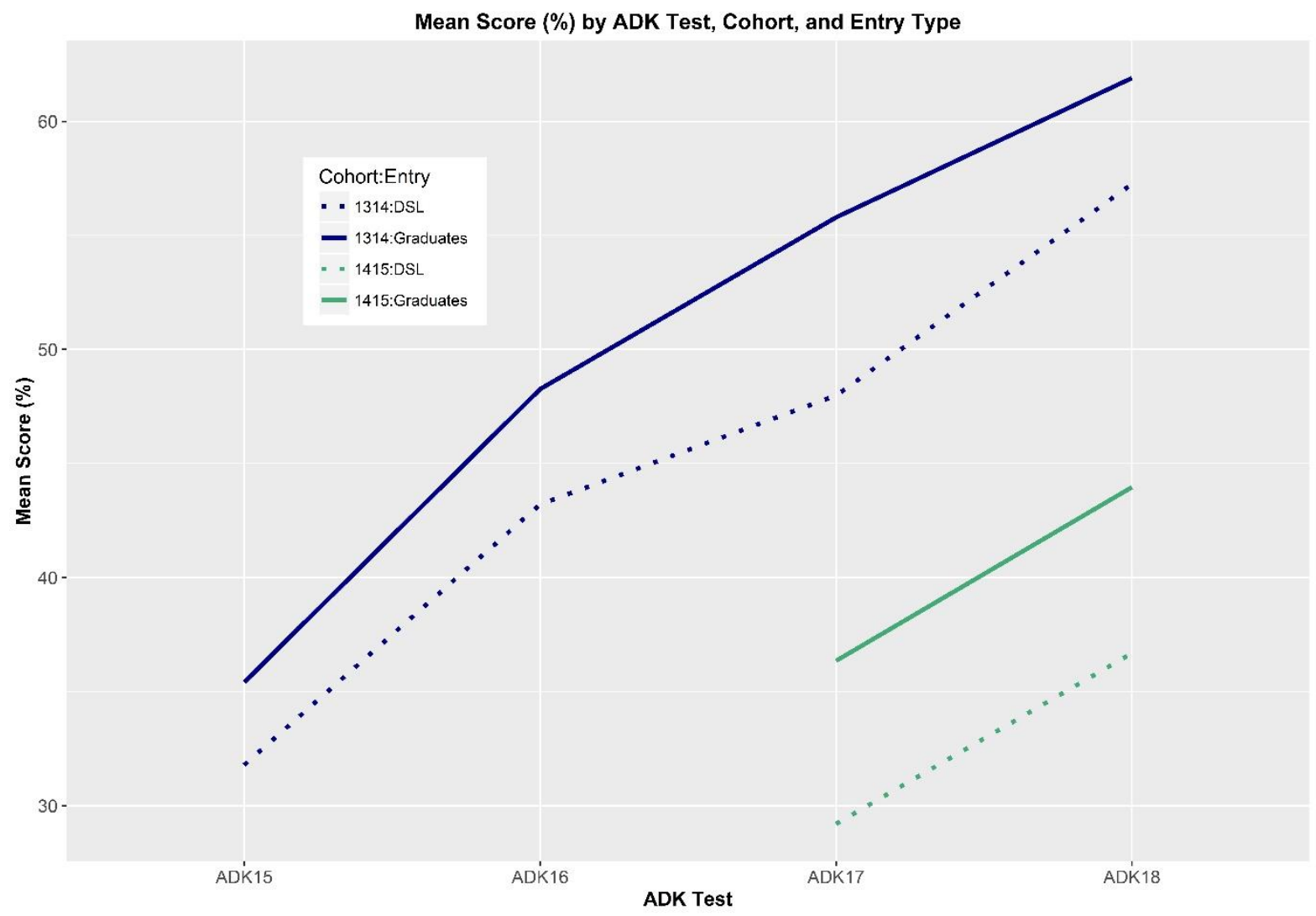


Table 1: Means and SDs by Cohort, ADK, and Entry Type

\begin{tabular}{cccccc}
\hline Cohort & ADK & Entry & $\mathbf{N}$ & $\mathbf{M}(\%)$ & SD(\%) \\
\hline $2013-14$ & ADK15 & Graduate & 8 & 35.42 & 10.78 \\
\cline { 3 - 6 } $2013-14$ & ADK15 & DSL & 53 & 31.79 & 8.95 \\
\cline { 2 - 5 } $2013-14$ & ADK16 & Graduate & 8 & 48.27 & 11.27 \\
\cline { 3 - 5 } $2013-14$ & ADK16 & DSL & 53 & 43.47 & 10.87 \\
\cline { 2 - 5 } $2013-14$ & ADK17 & Graduate & 8 & 55.80 & 6.78 \\
\cline { 3 - 5 } $2013-14$ & ADK17 & DSL & 54 & 47.98 & 9.52 \\
\cline { 2 - 5 } $2013-14$ & ADK18 & Graduate & 8 & 61.90 & 7.65 \\
$2013-14$ & ADK18 & DSL & 54 & 57.25 & 10.29 \\
\hline $2014-15$ & ADK17 & Graduate & 10 & 36.35 & 6.97 \\
$2014-15$ & ADK17 & DSL & 54 & 29.20 & 6.79 \\
\cline { 2 - 6 } $2014-15$ & ADK18 & Graduate & 10 & 43.96 & 8.73 \\
$2014-15$ & ADK18 & DSL & 54 & 35.87 & 8.48 \\
\hline
\end{tabular}




\section{Discussion}

This is perhaps the first study comparing the academic performance of graduate students and direct school leavers in an undergraduate dental programme. The results of this exploratory study show that graduate-entry students perform better on academic assessments than direct school leavers during the early years. These differences are most probably related to the prior knowledge of graduate students from biomedical sciences conferring an advantage, at least in the early years. Similar findings are reported in studies on medical students (3). However, the differences in academic performance of graduate-entry and direct school leavers in undergraduate medical programmes are reported to diminish by the time they reach graduation ( 2 , 6). Therefore, better academic performance in the early part of the course, as observed in our study, does not build a strong argument to support graduate-entry criteria into dentistry. It would be interesting to see whether the observed differences in academic performance of graduate-entry and direct school leavers are maintained over the entire length of the undergraduate dental programme by extending the number of test occasions over which data is analysed, and looking specifically for interactions between ADK and Entry.

Although the graduate students were a small group in each cohort, we believe this analytic approach was appropriate in that it allows clear identification of the effects of each factor and provides an easily interpretable initial, exploratory, analysis of these effects. The assumptions of the analysis were met by the data (normality, skew, kurtosis, homogeneity of variance and residuals). ANOVAs are generally considered more robust to differences in sample size than possible alternative analyses (19). The proportions of Graduate to DSL students was similar across cohorts, so the variation in sample size was not confounded with other factors. 
There remain, however, several limitations of this study to be addressed in future work. Firstly, the data reported is from a single undergraduate dental programme and it would be worthwhile exploring differences in academic performance between direct school leavers and graduate entrants at other dental schools. Moreover, the graduate students included in this study were non-homogeneous with regards to their previous degree(s) and had diverse backgrounds. Graduate students comprised those with a degree in medicine as well as postgraduate degrees including masters and doctorate qualifications. A small number of graduates also had a degree in dentistry from overseas. Similarly, there was a wide variation in work experiences of students. The afore-mentioned factors along with differences in the learning styles, motivation levels, prior experience of assessments at a university level could have all potentially contributed to their academic performance and, in turn, influenced the results of this study. However, these differences could not be factored into the design and analysis for this study due to the relatively small sample sizes.

Building on the current work, we hope to increase our sample size and the timeframe over which data is collected in future. This will enable more sophisticated analyses which can accommodate demographic information and we would encourage the development of inter-institutional work in future to address the limitations of this design. Moreover, there is merit in considering the use of qualitative methods to gain a deeper understanding of the learning approaches used by students and how these impact on their performance in the examinations.

Previous studies on medical students have shown no differences in the overall performance of graduate-entry students in undergraduate medical programmes $(2$, 20). Like medicine, academic performance only represents one of the several dimensions of skills and attributes expected from dental students and graduates. 
Further research is also required to investigate the differences in clinical and affective skills including communication skills, team-working, professionalism, emotional intelligence, and research aptitude, to name a few. Such research would be valuable in gathering evidence regarding the performance of students in dental undergraduate programmes based on their previous educational backgrounds. This may not only inform the admission criteria to help select the best candidates for entry into dentistry but also allow the dental educators to tailor the teaching and learning strategies to address the specific learning needs of students.

\section{Conclusions}

This is the first study exploring the differences in the academic performance of graduate-entry and direct school leavers in an undergraduate dental programme progress test. Applied dental knowledge of all students was assessed using the same tests irrespective of the entry-type. The results show that the academic performance of graduate students was better than the direct school leavers in years 2 and 3 . Further research is required to compare the performance of students longitudinally for the entire duration of undergraduate dental programmes.

\section{Disclosure}

None of the authors have any conflict of interest. 


\section{References}

4. McAndrew R, Salem-Rahemi M. Advice and guidance on the admissions process to UK dental schools. Dent Update. 2013 Mar;40(2):129-32, 135-8, $141-2$.

5. Rolfe IE, Ringland C, Pearson SA. Graduate entry to medical school? Testing some assumptions. Med Educ. 2004 Jul;38(7):778-86.

6. Dodds AE, Reid KJ, Conn JJ, Elliott SL, McColl GJ. Comparing the academic performance of graduate- and undergraduate-entry medical students. Med Educ. 2010 Feb;44(2):197-204.

7. Calvert MJ, Ross NM, Freemantle N, Xu Y, Zvauya R, Parle JV. Examination performance of graduate entry medical students compared with mainstream students. J R Soc Med. 2009 Oct;102(10):425-30.

8. Reid KJ, Dodds AE, McColl GJ. Clinical assessment performance of graduateand undergraduate-entry medical students. Med Teach. 2012;34(2):168-71.

9. Shehmar M, Haldane T, Price-Forbes A, Macdougall C, Fraser I, Peterson S,Peile E. Comparing the performance of graduate-entry and school-leaver medical students. Med Educ. 2010 Jul;44(7):699-705.

10.Duggan EM, O'Tuathaigh CM, Horgan M, O'Flynn S. Enhanced research assessment performance in graduate vs. undergraduate-entry medical students: implicationsfor recruitment into academic medicine. QJM. 2014 Sep;107(9):735-41.

11. Marvão P, Neto I, Castelo-Branco M, Ponte J, Portela M, Costa P, Costa MJ. An exploratory study on the contribution of graduate entry students personality to the diversity of medical student populations. Perspect Med Educ. 2014 $\operatorname{Dec} ; 3(6): 431-42$.

12. James D, Ferguson E, Powis D, Bore M, Munro D, Symonds I, Yates J. Graduate entry to medicine: widening psychological diversity. BMC Med Educ. 2009 Nov 13; 9:67.

13. McHarg J, Kay EJ. Designing a dental curriculum for the twenty first century. $\mathrm{Br}$ Dent J 2009: 207: 493-497.

14. McHarg J, Kay EJ. The anatomy of a new dental curriculum. Br Dent J 2008: 204: 635-638. 
15. Van der Vleuten CPM, Verwijnen GM, Wijnen WHFW. Fifteen years of experience with progress testing in a problem-based learning curriculum. Med Teach. 1996; 18:103-10.

16. Blake JM, Norman GR, Keane DR, Barber Mueller C, Cunnington J, Didyk N. Introducing progress testing in McMaster University's problem-based medical curriculum: psychometric properties and effect on learning. Acad Med. 1996; 71:1002-7.

17. Freeman A, Ricketts C. Choosing and designing knowledge assessments: experience at a new medical school. Med Teach. 2010; 32:578-81.

18. Schuwirth L, Bosman G, Henning R, Rinkel R, Wenink A. Collaboration on progress testing in medical schools in the Netherlands. Med Teach. 2010; 32:476-9.

19. Bennett J, Freeman A, Coombes L, Kay L, Ricketts C. Adaptation of medical progress testing to a dental setting. Med Teach. 2010; 32(6):500-2.

20. Ali K, Coombes L, Kay E, Tredwin C, Jones G, Ricketts C, Bennett J. Progress testing in undergraduate dental education: the Peninsula experience and future opportunities. Eur J Dent Educ. 2015 Apr 15. doi: 10.1111/eje.12149.

21. R Development Core Team (2008). R: A language and environment for statistical computing. R Foundation for Statistical Computing, Vienna, Austria. ISBN 3-900051-07-0, Available at: HTTP://www.R-PROJECT.ORG

22. Keselman HJ, Huberty CJ, Lix LM, Olejnik S, Cribbie RA, Donahue B, Kowalchuk RK, Lowman LL, Petoskey MD, Keselman JC, Levin JR. Statistical practices of educational researchers: An analysis of their ANOVA, MANOVA, and ANCOVA analyses. Review of Educational Research. 1998 Sep 1;68(3):350-86.

23. Harth SC, Biggs JS, Thong YH. Mature-age entrants to medical school: a controlled study of sociodemographic characteristics, career choice and job satisfaction. Med Educ. 1990 Nov;24(6):488-98. 